\title{
Total alkaloids of Rubus aleaefolius Poir inhibit hepatocellular carcinoma growth in vivo and in vitro via activation of mitochondrial-dependent apoptosis
}

\author{
JINYAN ZHAO ${ }^{1,2}$, XUZHENG CHEN $^{1}$, WEI LIN ${ }^{1,2}$, GUANGWEN WU $^{1}$, \\ QUNCHUAN ZHUANG ${ }^{1,2}$, XIAOYONG ZHONG ${ }^{1}$, ZHENFENG HONG $^{1}$ and JUN PENG ${ }^{1,2}$ \\ ${ }^{1}$ Academy of Integrative Medicine, ${ }^{2}$ Fujian Key Laboratory of Integrative Medicine on Geriatrics, \\ Fujian University of Traditional Chinese Medicine, Fuzhou, Fujian 350122, P.R. China
}

Received November 5, 2012; Accepted December 20, 2012

DOI: $10.3892 /$ ijo.2013.1779

\begin{abstract}
The aim of this study was to evaluate the therapeutic efficacy of Rubus aleaefolius Poir total alkaloids (TARAP) against hepatocellular carcinoma growth in vivo and in vitro, and to investigate the possible molecular mechanisms mediating its biological activity. Nude mice were implanted with HepG2 human hepatocellular carcinoma cells and fed with vehicle (physiological saline) or $3 \mathrm{~g} / \mathrm{kg} / \mathrm{d}$ dose of TARAP, 5 days per week, for 21 days. The in vivo efficacy of TARAP against tumor growth was investigated by evaluating its effect on tumor volume and tumor weight in mice with HCC xenografts and its adverse effect was determined by measuring the body weight gain. The in vitro effect of TARAP on the viability of HepG2 cells was determined by MTT assay. HepG2 cell morphology was observed via phase-contrast microscopy. Apoptosis in tumor tissues or in HepG2 cells was analyzed by TUNEL assay or FACS analysis with Annexin V/PI, respectively. The loss of mitochondrial membrane potential in HepG2 cells was determined via JC-1 staining followed by FACS analysis. Activation of caspase- 9 and -3 in HepG2 cells was examined by a colorimetric assay. The mRNA and protein expression of Bcl-2 and Bax in tumor tissues were measured by RT-PCR and immunohistochemistry. TARAP reduced tumor volume and tumor weight, but had no effect on the body weight gain in HCC mice. TARAP decreased the viability of HepG2 cells and induced cell morphological changes in vitro in a dose- and
\end{abstract}

Correspondence to: Dr Jun Peng, Academy of Integrative Medicine and Fujian Key Laboratory of Integrative Medicine on Geriatrics, Fujian University of Traditional Chinese Medicine, 1 Huatuo Road, Shangjie Minhou, Fuzhou, Fujian 350122, P.R. China

E-mail: pjunlab@hotmail.com

Dr Zhenfeng Hong, Academy of Integrative Medicine, Fujian University of Traditional Chinese Medicine, 1 Huatuo Road, Shangjie Minhou, Fuzhou, Fujian 350122, P.R. China

E-mail: zfhong1953@163.com

Key words: total alkaloids of Rubus aleaefolius Poir, hepatocellular carcinoma, apoptosis, mitochondrion time-dependent manner. In addition, TARAP induced apoptosis both in tumor tissues and in HepG2 cells. Moreover, TARAP treatment resulted in the collapse of mitochondrial membrane potential in HepG2 cells, as well as the activation of caspase-9 and -3 . Furthermore, administration of TARAP increased the pro-apoptotic Bax/Bcl-2 ratio in HCC mouse tumors, at both transcriptional and translational levels. TARAP inhibits hepatocellular carcinoma growth both in vivo and in vitro probably through the activation of mitochondrial-dependent apoptosis, which may, in part, explain its anticancer activity. These results suggest that total alkaloids in Rubus aleaefolius Poir may be a potential novel therapeutic agent for the treatment of hepatocellular carcinoma and other cancers.

\section{Introduction}

Hepatocellular carcinoma (HCC) is the fifth most common cancer and the third most common cause of cancer-related death (1). Although surgical resection offers the best prognosis for long-term survival, most of HCC patients are not suitable for surgical resection because at the time of diagnosis the tumor may be too large or has expanded into nearby major blood vessels or metastasized (2,3). Therefore, chemotherapy continues to be one of the major non-surgical therapeutic approaches for patients with advanced HCC. However, because of the inherently chemotherapy-resistant nature of $\mathrm{HCC}$ and the unacceptable adverse effects of most currently-used chemotherapeutic agents, the systemic cytotoxic chemotherapy is not always effective at improving patient survival (4). Thus, developing novel anticancer therapeutic agents is urgently needed. Recently, natural products have received great interest as they have relatively few side-effects compared to modern chemotherapeutics and have long been used clinically to treat various diseases including cancer (5-8). Rubus aleaefolius Poir (Rubus L.) is a major genus of the Rosaceae, widely distributed all over the world. This herb is generally used as a folk medicine to treat various types of hepatitis in southern part of Fujian Province, China. Previously, we reported that the ethylacetate and then-butanol fractions of Rubus aleaefolius Poir displays in vivo hepatoprotective effects in carbon tetrachloride-induced acute liver injury mouse model (9). In addition, modern pharmacological studies 
have proposed that Rubus aleaefolius Poir contains antitumor activity $(10,11)$. However, the precise mechanisms of its potential tumoricidal activity remain unclear.

Apoptosis eliminates redundant or damaged cells and hence is crucial for maintaining tissue homeostasis. Disturbed regulation of apoptosis contributes to a variety of diseases, including autoimmunity, neurodegeneration and cancer (12-14). Mitochondria play an important role in apoptotic death, which is highly regulated by Bcl-2 family proteins including both anti-apoptotic members (such as Bcl-2 and Bcl-XL) and pro-apoptotic members (such as Bax and Bak). It has been demonstrated that after activation, the pro-apoptotic Bax or Bak is sufficient to induce mitochondrial outer membrane permeabilization (MOMP) (15-17), releasing pro-apoptotic proteins such as cytochrome $c$ and Diablo/Smac that eventually lead to the activation of aspartate-directed cysteine proteases (caspases) and nucleases, resulting in destruction of the cell (18-20). The anti-apoptotic $\mathrm{Bcl}-2$ protein protects cells from apoptosis probably by interacting with Bax and inhibiting Bax-mediated MOMP (17,21-23). The sensitivity of cells to apoptotic stimuli can depend on the ratio of pro- and anti-apoptotic Bcl-2 proteins. Alteration of the ratio by aberrant expression of these proteins impairs the normal apoptotic program contributing to cancer development $(24,25)$. Therefore, promoting cell apoptosis has been suggested as a promising strategy for the development of anticancer drugs. Using mouse xenograft model and hepatocellular carcinoma cell line, in the present study we evaluated the antitumor effect of total alkaloids of Rubus aleaefolius Poir (TARAP) in vivo and in vitro, and investigated the possible molecular mechanisms mediating its biological activity.

\section{Materials and methods}

Materials and reagents. Dulbecco's modified Eagle's medium (DMEM), fetal bovine serum (FBS), penicillin-streptomycin, Trypsin-EDTA, TRIzol reagent and 5,5',6,6'-tetrachloro1,1',3,3'-tetraethyl-benzimidazol-carbocyanine iodide (JC-1), and caspase -3 and -9 colorimetric protease assays were purchased from Invitrogen (Carlsbad, CA, USA). SuperScript II reverse transcriptase was obtained from Promega (Madison, WI, USA). Antibodies for Bax and Bcl-2 were obtained from Santa Cruz Biotechnology Inc. (Santa Cruz, CA, USA), a fluorescein isothiocyanate (FITC)-conjugated Annexin V apoptosis detection kit was obtained from Becton-Dickinson (San Jose, CA, USA). All other chemicals, unless otherwise stated, were obtained from Sigma Chemicals (St. Louis, MO, USA).

Preparation and content of total alkaloids of Rubus aleaefolius Poir (TARAP). The preparation of TARAP was performed as described (26). The roots of Rubus alceifolius Poir were collected from Anxi of Fujian Province, identified and authenticated by experts in our University, and the alkaloids were extracted. The herb powder $(1 \mathrm{~g})$ was extracted with $50 \mathrm{ml}$ chloroform:methanol:ammonia solution $(15: 4: 3)$ for $2 \mathrm{~h}$ in an ice bath, sonicated for $30 \mathrm{~min}$, brought to room temperature and filtered. The filtered solution was collected and dessicated. The resultant residue was dissolved by $2 \mathrm{ml}$ of $2 \%$ sulfuric acid solution and filtered. The filter paper and residue were re-washed with $2 \mathrm{ml}$ of $2 \%$ sulfuric acid solution and with buffer solution (pH 3.6). Buffer was then added to make a final volume of $50 \mathrm{ml}$ and the solution saved for future use. Acid dye colorimetry was used to measure total alkaloid content. Total alkaloid content was $0.81 \mathrm{mg}$ of alkaloid per gram of initial herb powder.

Cell culture. Human hepatocellular carcinoma cell HepG2 cells were obtained from American Type Culture Collection (ATCC, Manassas, VA, USA). The cells were grown in DMEM containing $10 \%(\mathrm{v} / \mathrm{v}) \mathrm{FBS}$, and $100 \mathrm{U} / \mathrm{ml}$ penicillin and $100 \mu \mathrm{g} / \mathrm{ml}$ streptomycin in a $37^{\circ} \mathrm{C}$ humidified incubator with $5 \% \mathrm{CO}_{2}$. The cells were subcultured at $80-90 \%$ confluency.

In vivo tumor xenograft study. HepG 2 cells were grown in culture and then detached by trypsinization, washed and resuspended in serum-free DMEM. Six-week-old athymic BALB/c nu/nu male mice were given an s.c. injection of $4 \times 10^{6} \mathrm{HepG} 2$ cells mixed with Matrigel (1:1) in the right flank to initiate tumor growth. After 7 days of xenograft implantation when tumor size reached $3 \mathrm{~mm}$ in diameter, mice were randomly divided into two groups and gavaged with the following: i) control group $(n=10)$, physiological saline (PS); and ii) TARAP group $(\mathrm{n}=10), 3 \mathrm{~g} / \mathrm{kg} / \mathrm{d}$ dose of TARAP in PS. All treatments were given 5 days a week for 21 days. Body weight and diet consumption were recorded twice weekly throughout the study. Tumor sizes were measured twice weekly and volume was calculated as reported recently (27). At the end of experiment, tumors were excised and weighed, and part of tumor was fixed in buffered formalin and the remaining was stored at $-80^{\circ} \mathrm{C}$ for molecular analyses.

Evaluation of cell viability by MTT assay. Cell viability was assessed by the 3-(4,5-dimethylthiazol-2-yl)-2,5-diphenyltetrazolium bromide (MTT) colorimetric assay. HepG2 cells were seeded into 96 -well plates at a density of $1 \times 10^{5}$ cells $/ \mathrm{ml}$ in $0.1 \mathrm{ml}$ medium. The cells were treated with various concentrations of TARAP for 24, 48 and $72 \mathrm{~h}$. Treatment with $0.5 \%$ DMSO was included as vehicle control. At the end of the treatment, $10 \mu \mathrm{l}$ MTT [5 mg/ml in phosphate-buffered saline (PBS)] were added to each well, and the samples were incubated for an additional $4 \mathrm{~h}$ at $37^{\circ} \mathrm{C}$. The purple-blue MTT formazan precipitate was dissolved in $100 \mu \mathrm{l}$ DMSO. The absorbance was measured at $570 \mathrm{~nm}$ using an ELISA reader (BioTek, Model ELX800, Winooski, VT, USA).

Observation of morphologic changes. HepG2 cells were seeded into 6 -well plates at a density of $2 \times 10^{5}$ cells/well in $2 \mathrm{ml}$ medium. The cells were treated with various concentrations of TARAP for $48 \mathrm{~h}$. Cell morphology was observed using a phase-contrast microscope (Olympus, Japan). The photographs were taken at a magnification of $\mathrm{x} 200$.

Detection of apoptosis by TUNEL. The TUNEL reaction was carried out after treatment with TARAP as previously described (28). Briefly, sequential $4 \mu \mathrm{m}$ tissue sections were adhered to silane-coated slides and allowed to dry at room temperature (RT). Subsequently, sections were deparaffinized and rehydrated. Protein digestion was done by incubating tissue sections in $20 \mathrm{mg} / \mathrm{ml}$ proteinase $\mathrm{K}$ (Worthington Co.,Lakewood, $\mathrm{CO}, \mathrm{USA}$ ) for $15 \mathrm{~min}$ at RT. Endogenous peroxidase was inactivated with $2 \% \mathrm{H}_{2} \mathrm{O}_{2}$ in distilled water $\left(\mathrm{dH}_{2} \mathrm{O}\right)$ for $5 \mathrm{~min}$, RT. The labelling mixture containing biotinylated dUTP in TdT enzyme buffer was added to sections and incubated at $37^{\circ} \mathrm{C}$ in an humi- 
fied chamber for $1 \mathrm{~h}$. After stopping the enzymatic reaction, sections were rinsed with PBS, covered with anti-digoxigenin peroxidase conjugate and incubated for $30 \mathrm{~min}$ at RT in an humified chamber. Then, sections were incubated in TBS with $0.05 \%$ diaminobenzidine (DAB) plus $3 \% \mathrm{H}_{2} \mathrm{O}_{2}$ until colour development was achieved. Finally, sections were washed, counterstained in haematoxylin, dehydrated and mounted with DPX (Panreac SA, Barcelona, Spain), and as a negative control active TdT buffer was replaced by the kit equilibration buffer.

Detection of apoptosis by flow cytometry analysis with Annexin V/PI staining. After incubation with various concentrations of TARAP, apoptosis of HepG2 cells was determined by flow cytometry analysis using a fluorescenceactivated cell sorting (FACS)Calibur (Becton-Dickinson) and Annexin V-fluorescein isothiocyanate (FITC)/propidium iodide (PI) kit. Staining was performed according to the manufacturer's instructions. The percentage of cells in early apoptosis was calculated by Annexin V-positivity and PI-negativity, while the percentage of cells in late apoptosis was calculated by Annexin V-positivity and PI-positivity.

Measurement of mitochondrial membrane potential $(\Delta \Psi m)$ by flow cytometric analysis with JC-1 staining. JC-1 is a cationic dye that exhibits potential-dependent accumulation in mitochondria, indicated by a fluorescence emission shift from green to red, which thus can be used as an indicator of mitochondrial potential. In this experiment, $1 \times 10^{6}$ treated HepG 2 cells were resuspended after trypsinization in $1 \mathrm{ml}$ of medium and incubated with $10 \mu \mathrm{g} / \mathrm{ml}$ of $\mathrm{JC}-1$ at $37^{\circ} \mathrm{C}, 5 \% \mathrm{CO}_{2}$, for $30 \mathrm{~min}$. Both red and green fluorescence emissions were analyzed by flow cytometry after JC-1 staining.

Analysis of caspase activation. The activities of caspase-3 and -9 were determined by a colorimetric assay using the caspase- 3 and -9 activation kits, following the manufacturer's instructions. Briefly, after treatment with various concentrations of TARAP for $48 \mathrm{~h}$, HepG 2 cells were lysed with the lysis buffer provided by the manufacturer, for $30 \mathrm{~min}$ on ice. The lysed cells were centrifuged at $16,000 \mathrm{x}$ g for $10 \mathrm{~min}$. The protein concentration of the clarified supernatant was determined and $100 \mu \mathrm{g}$ of the protein were incubated with $50 \mu \mathrm{l}$ of the colorimetric tetrapeptides, Asp-Glu-Val-Asp (DEAD)-p-nitroaniline (pNA) (specific substrate of caspase-3) or Leu-Glu-His-Asp (LEHD)-pNA (specific substrate of caspase-9) at $37^{\circ} \mathrm{C}$ in the dark for $2 \mathrm{~h}$. Samples were read at $405 \mathrm{~nm}$ in an ELISA plate reader (BioTek, Model ELX800). The data were normalized to the activity of the caspases in control cells (treated with $0.5 \%$ DMSO vehicle) and are presented as 'fold of control'.

RNA extraction and RT-PCR analysis. The expression of Bax and Bcl-2 genes were detected by RT-PCR. Total RNA was isolated with TRIzol Reagent. Oligo(dT)-primed RNA (1 $\mu \mathrm{g})$ was reverse-transcribed with SuperScript II reverse transcriptase (Promega) according to the manufacturer's instructions. The obtained cDNA was used to determine the mRNA amount of Bcl-2 or Bax by PCR. GAPDH was used as an internal control. The sequences of the primers used for amplification of Bcl-2, Bax and GAPDH transcripts are as follows: Bcl-2 forward: 5'-CAG CTG CAC CTG ACG CCC TT-3 and reverse:
5'-GCC TCC GTT ATC CTG GAT CC-3'; Bax forward: 5'-TGC TTC AGG GTT TCA TCC AGG-3' and reverse: 5'-TGG CAA AGT AGA AAA GGG CGA-3'; GAPDH forward: 5'-GT CAT CCA TGA CAA CTT TGG-3' and reverse: 5'-GA GCT TGA CAA AGT GGT CGT-3'.

Immunohistochemistry analysis. Immunohistochemical staining for Bcl-2 and Bax was performed as previously (29). The sections were deparaffinised in xylene and hydrated through graded alcohols. Antigen unmasking was performed using heat treatment in a microwave oven at $750 \mathrm{~W}$ for $7 \mathrm{~min}$ in a container with $10 \mathrm{mM}$ sodium citrate buffer, $\mathrm{pH}$ 6.0. Sections were allowed to cool in the buffer at room temperature for $30 \mathrm{~min}$ and were rinsed in deionised water three times for $2 \mathrm{~min}$ each. The endogenous peroxidase activity was blocked with $3 \%(\mathrm{v} / \mathrm{v})$ hydrogen peroxide for $10 \mathrm{~min}$. The sections were incubated with $1 \%$ bovine serum albumin in order to decrease non-specific staining and reduce endogenous peroxidase activity. The sections were then incubated with Bax or Bcl-2 antibody (all in 1:200 dilution, Santa Cruz Biotechnology Inc.) at $4^{\circ} \mathrm{C}$ overnight using a staining chamber. Primary antibodies were diluted (1:100) in PBS. After rinsing three times in PBS, sections were incubated in biotinylated goat anti-rabbit IgG (Boshide, Wuhan, China) followed by avidin-biotin-peroxidase complex (Vector). Immunostaining was visualized by incubation in 3,3-diaminobenzidine (DAB) as a chromogen. Sections were counterstained with haematoxylin. The Bax and Bcl-2 positive immunostainings were evaluated by the use of Nikon Eclipse 50i microscope (x40 objective). The evaluation of Bax and Bcl-2 expression was analysed in 6 different fields and the mean percentage of $\mathrm{Bax}$ or $\mathrm{Bcl}-2$ positive staining was evaluated.

Statistical analysis. All data are the means of three determinations. The data were analyzed using the SPSS package for Windows (Version 11.5). Statistical analysis of the data was performed with Student's t-test and ANOVA. Differences with $\mathrm{P}<0.05$ were considered statistically significant.

\section{Results}

TARAP inhibited hepatocellular carcinoma growth in vivo and in vitro. The anticancer activity of TARAP in vivo was determined via examining tumor volume and weight in hepatocellular carcinoma (HCC) xenograft mice, whereas its side-effects were determined by measuring the body weight change. As shown in Fig. 1A, tumor volume per mouse was $1,900 \pm 167 \mathrm{~mm}^{3}$ or $1,370 \pm 98 \mathrm{~mm}^{3}$ in control or TARAP treated group, respectively, accounting for a $28 \%$ decrease in tumor volume $(\mathrm{P}<0.01)$. Consistently, TARAP treatment caused $39 \%$ decrease in tumor weight $(\mathrm{P}<0.01)$ compared with control $(0.97 \pm 0.21 \mathrm{~g}$ or $0.59 \pm 0.16 \mathrm{~g}$ per mouse in control or TARAP-treated group). In contrast, TARAP treatment did not affect body weight gain. These findings together demonstrated the in vivo antitumor efficacy of TARAP against human HCC tumor xenograft in nude mice without any apparent sign of toxicity. To evaluate the in vitro antitumor activity of TARAP, we performed MTT assay to examine its effect on the viability of human hepatocellular carcinoma HepG2 cells. As shown in Fig. 2, treatment with $0.25-1.0 \mathrm{mg} / \mathrm{ml}$ of TARAP for 24,48 


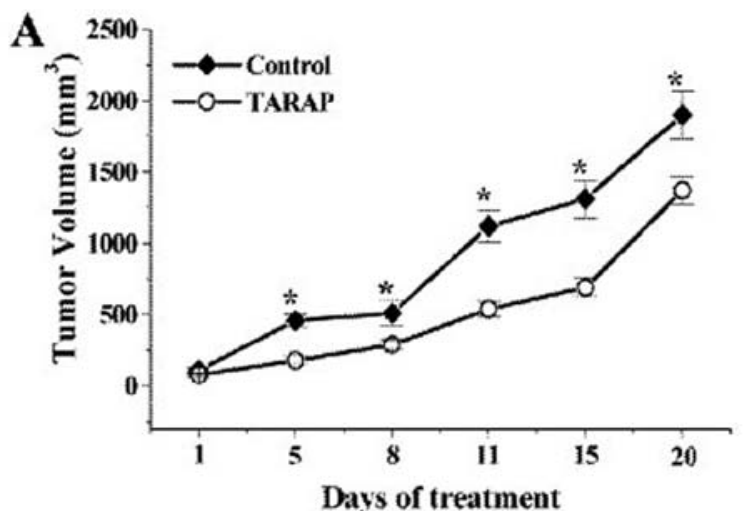

B

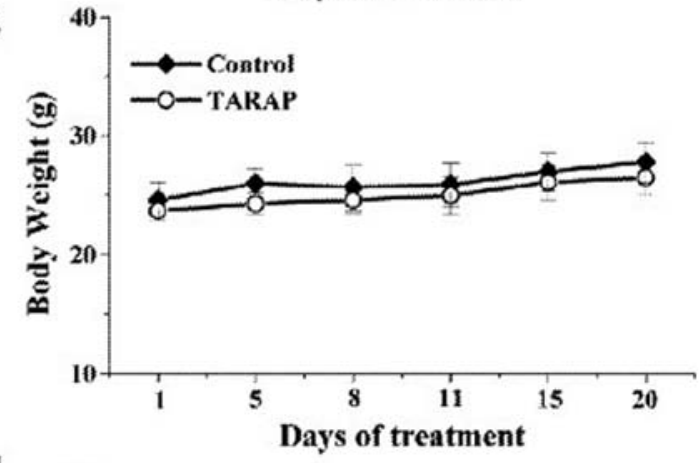

C

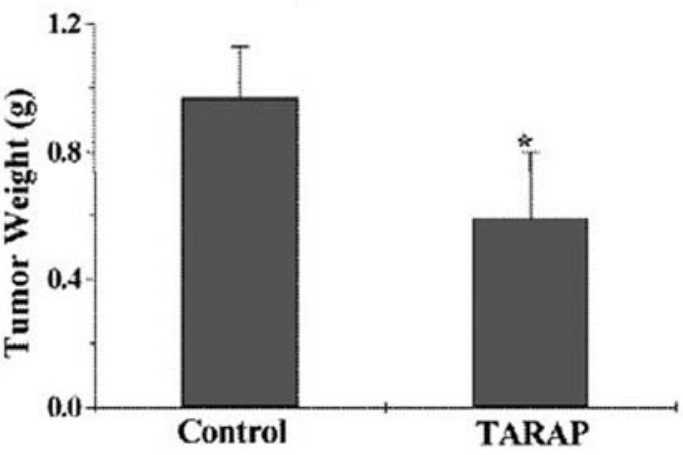

Figure 1. Effect of TARAP on tumor growth in mouse xenografts with human hepatocellular carcinoma HepG2 cells. After tumor development, the mice were given intra-gastric administration of $3 \mathrm{~g} / \mathrm{kg} / \mathrm{d}$ dose of TARAP or PBS daily, 5 days a week, for 21 days. (A) Tumor volume, (B) tumor weight and $(\mathrm{C})$ body weight were measured at the end of experiment. Data shown are averages with SD (error bars) from 10 mice in each group. ${ }^{*} \mathrm{P}<0.05$ vs. controls.

or $72 \mathrm{~h}$, respectively, reduced cell viability by $11-20,26-53$ or $39-65 \%$, compared to untreated control cells $(\mathrm{P}<0.01)$, indicating that TARAP inhibits the growth of HepG2 cells in a dose- and time-dependent manner. To further verify these results, we evaluated the effect of TARAP on HepG2 cell morphology that represents the healthy status of cells in culture. As shown in Fig. 3, untreated HepG2 cells appeared as densely packed and disorganized multilayers, whereas, many of the TARAP-treated cells were rounded, shrunken and detached from adjacent cells adhering to the plate or floating in the medium. Taken together, these data demonstrate that TARAP inhibits the growth of HepG2 cells. Taken together, it is suggested that TARAP inhibits hepatocellular carcinoma growth both in vivo and in vitro, without apparent adverse effects.

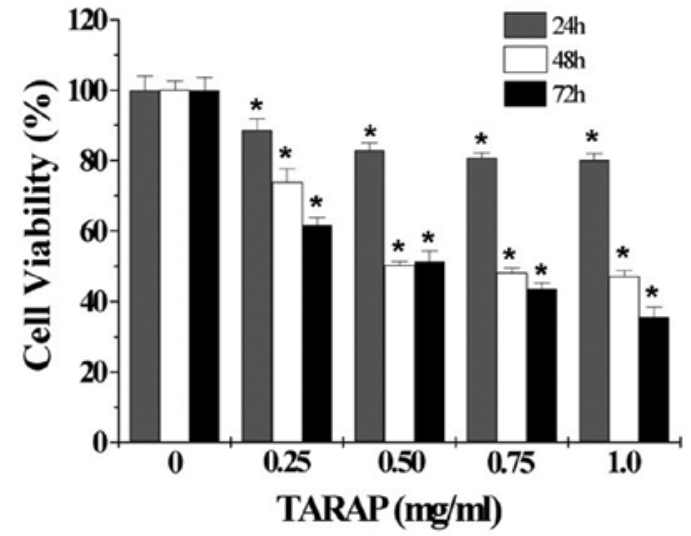

Figure 2. Effect of TARAP on the viability of HepG2 cells. Cells were incubated with various concentrations of TARAP for 24,48 or $72 \mathrm{~h}$. Cell viability was determined by the MTT assay. The data were normalized to the viability of control cells. Data are averages with SD (error bars) from at least three independent experiments. ${ }^{*} \mathrm{P}<0.05$ vs. control cells.

TARAP induces hepatocellular carcinoma cell apoptosis in vivo and in vitro. Cell apoptosis in HCC tumor tissues was determined via immunohistochemical (IHC) staining for TUNEL. As shown in Fig. 4A, the percentage of TUNEL-positive cells in control or TARAP-treated mouse group was $22.23 \pm 6.13$ or $83.83 \pm 12.24 \%$, respectively, indicating that TARAP treatment significantly induced cell apoptosis in HCC tumors. The apoptosis of HepG2 cells was evaluated by FACS analysis with Annexin V/PI staining. As shown in Fig. 4B and $\mathrm{C}$, the percentage of cells undergoing either early apoptosis or late apoptosis following treatment with $0,0.25,0.5,0.75$ and $1.0 \mathrm{mg} / \mathrm{ml}$ of TARAP was $9.18 \pm 1.32$, $17.5 \pm 3.41,21.92 \pm 3.49,33.1 \pm 3.31$ and $54.72 \pm 8.76 \%$, respectively $(\mathrm{P}<0.05$,). These data together demonstrate that TARAP promotes hepatocellular carcinoma cell apoptosis both in vivo and in vitro.

TARAP induces loss of mitochondrial potential $(\Delta \Psi m)$ and the activation of caspase-9 and -3 in HepG 2 cells. The effect of TARAP on the change of mitochondrial membrane potential in HepG2 cells was examined via JC-1 staining followed by FACS analysis. The membrane-permeant JC-1 dye displays potential-dependent accumulation in mitochondria, indicated by a fluorescence emission shift from green $(\sim 525 \mathrm{~nm})$ to red $(\sim 590 \mathrm{~nm})$. Therefore, collapse of mitochondrial potentail during apoptosis is indicated by a decrease in the ratio of red/green fluorescence intensity. As shown in Fig. 5, after treatment with $0,0.25,0.5,0.75$ and $1.0 \mathrm{mg} /$ $\mathrm{ml}$ of TARAP the JC-1 red/green fluorescent ratio in HepG2 cells was $9.08 \pm 1.896,3.38 \pm 0.348,2.69 \pm 0.275,2.34 \pm 0.282$ and $2.21 \pm 0.226$, respectively, suggesting that TARAP dosedependently induces the loss of mitochondrial membrane potential in hepatocellular carcinoma cells. To identify the downstream effectors in the apoptotic signaling pathway, the activation of caspase- 9 and caspase- 3 was examined by a colorimetric assay using specific chromophores, DEVD-pNA (specific substrate of caspase-3) and LEHD-pNA (specific substrate of caspase-9). As showed in Fig. 6, TARAP treatment significantly and dose-dependently induced activation 

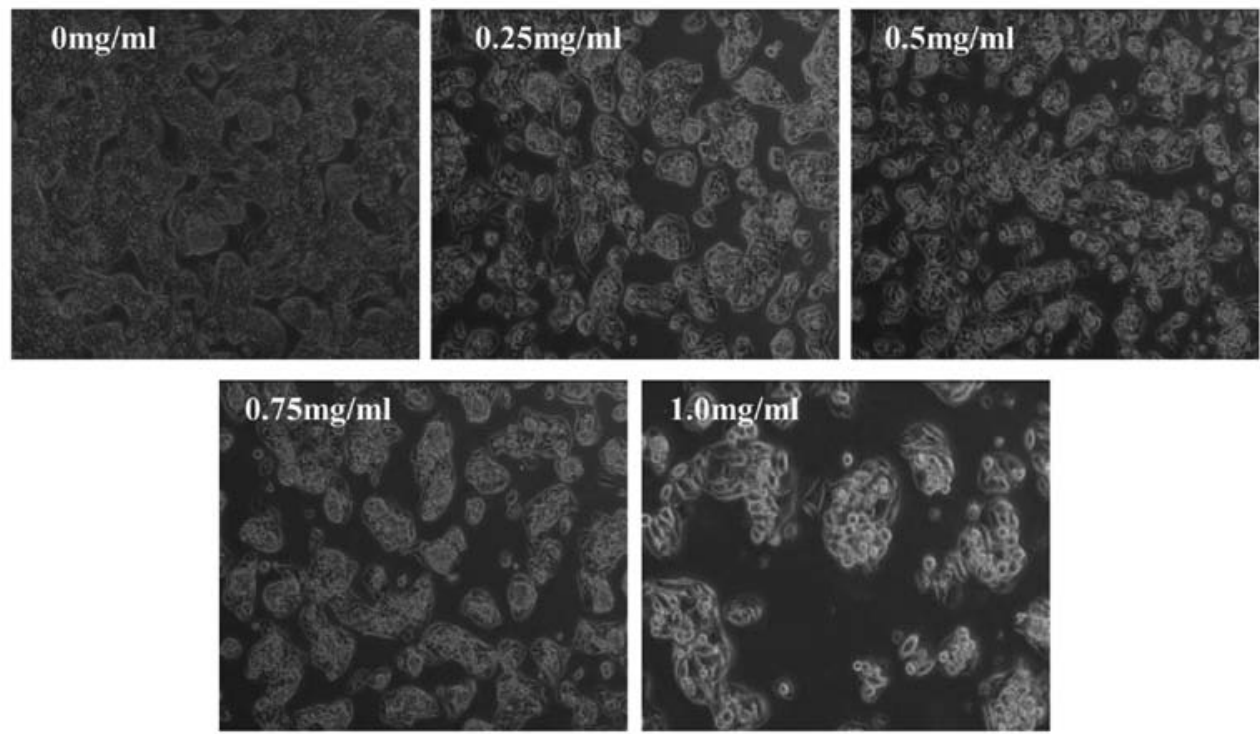

Figure 3. Effect of TARAP on the morphology of HepG2 cells. HepG2 cells were treated with the indicated concentrations of TARAP for 24 h and morphological changes were observed using phase-contrast microscopy. The photographs were taken at a magnification, x200. Images are representative of three independent experiments.

A

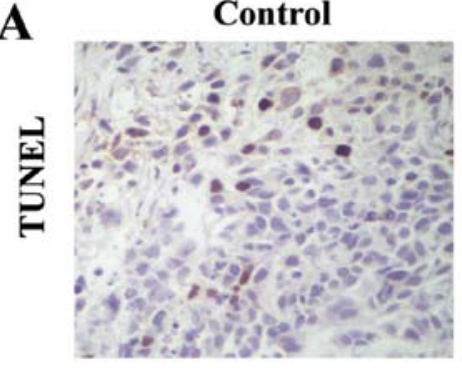

B

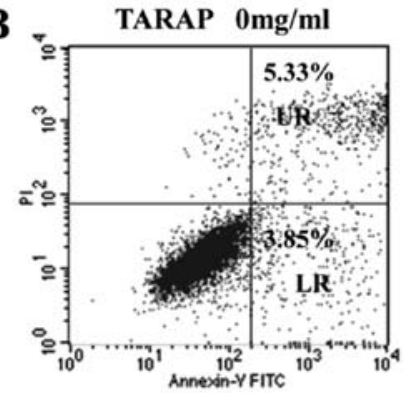

TARAP $0.75 \mathrm{mg} / \mathrm{ml}$

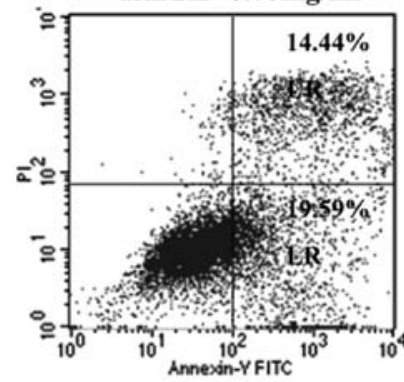

TARAP

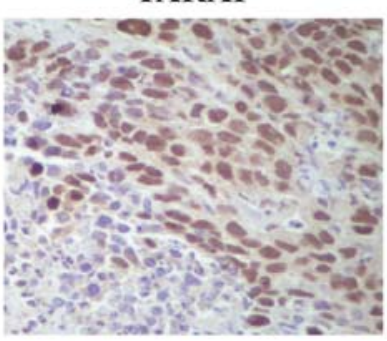

TARAP $0.25 \mathrm{mg} / \mathrm{ml}$
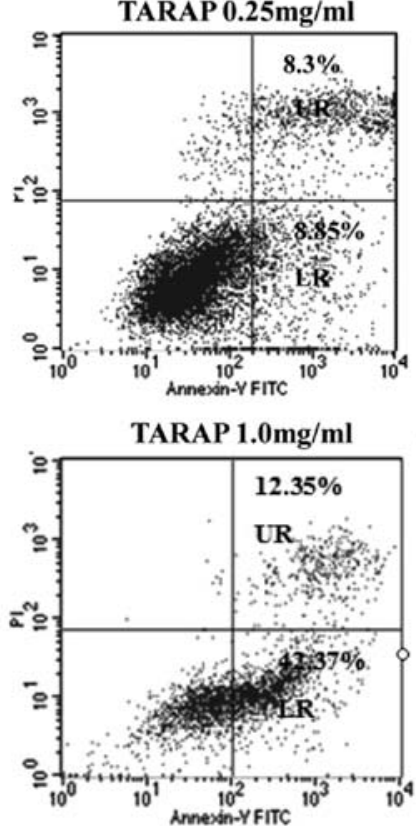

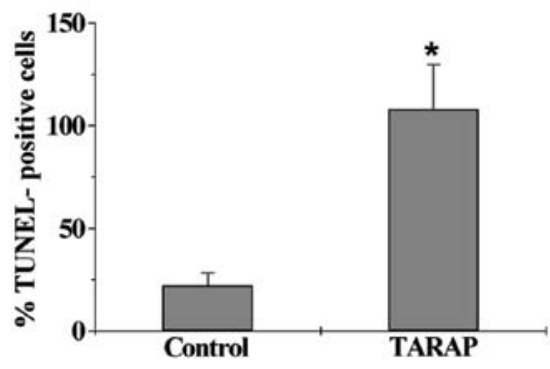

TARAP $0.5 \mathrm{mg} / \mathrm{ml}$

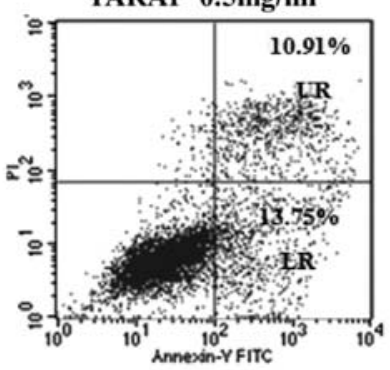

C

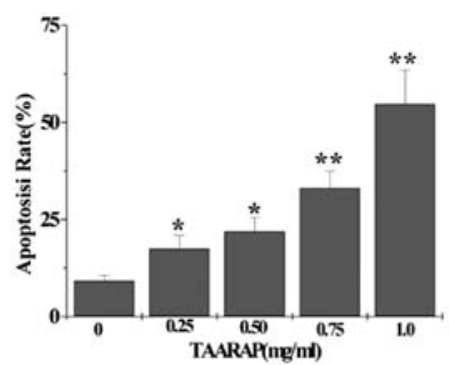

Figure 4. Effect of TARAP on apoptosis in both HCC xenograft mice and HepG2 cells. (A) At the end of the experiment, tumor tissues were processed for immunohistochemical (IHC) staining for TUNEL. The photographs are representative images taken at a magnification, $\mathrm{x} 400$. Quantification of IHC assay is presented as percentage of positively-stained cells. Data shown are averages with $\mathrm{SD}$ (error bars) from 10 mice in each group. "P<0.05 vs. controls. (B) HepG2 cells were treated with the indicated concentrations of TARAP for $24 \mathrm{~h}$, stained with Annexin V/PI and analyzed by FACS. Data shown are representative of three independent experiments. (C) Quantification of FACS analysis. Data shown are averages with SD (error bars) from three independent experiments. ${ }^{*} \mathrm{P}<0.05$, ${ }^{* *} \mathrm{P}<0.01$ vs. control cells. 
A

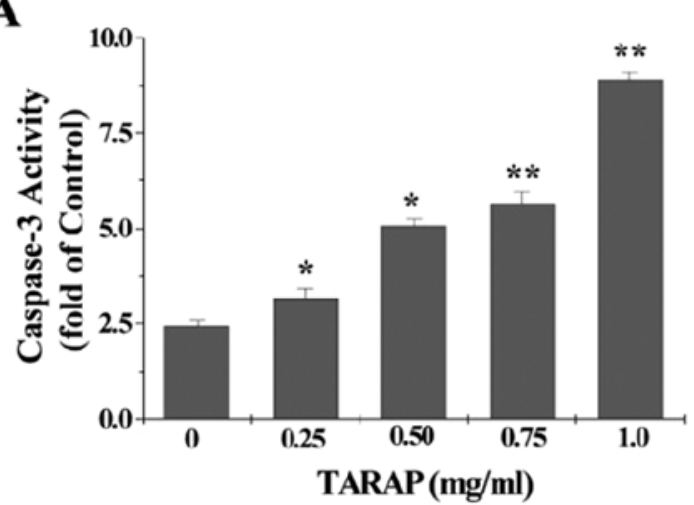

B

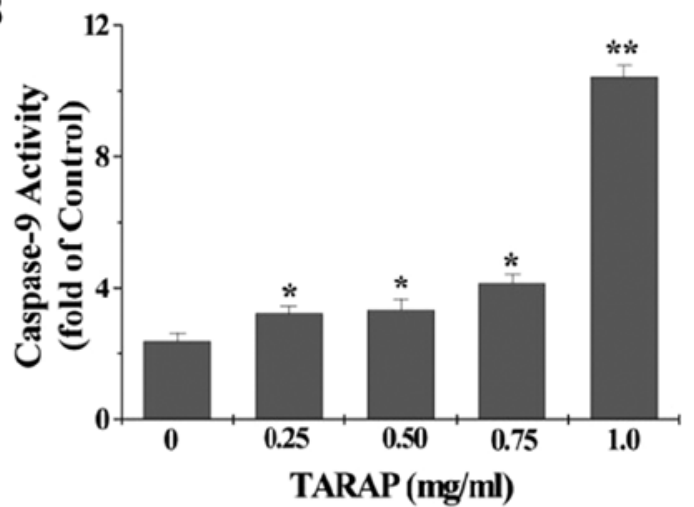

Figure 5. Effect of TARAP on the loss of mitochondrial membrane potential in HepG2 cells. (A) Cells were treated with the indicated concentrations of TARAP for $24 \mathrm{~h}$ and stained with JC-1. The mean JC-1 fluorescence intensity was detected using FACS analysis. Data shown are representative of three independent experiments. (B) Quantification of FACS analysis. Data shown are averages with SD (error bars) from three independent experiments. * $<0.01$ vs. control cells.

A

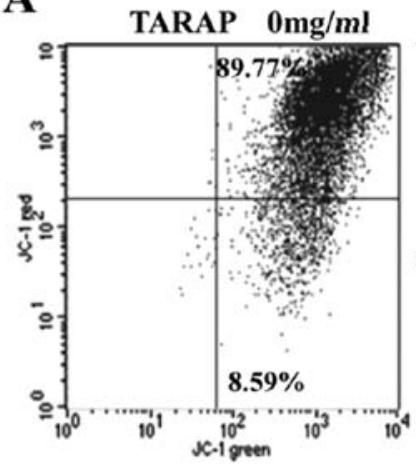

TARAP $0.75 \mathrm{mg} / \mathrm{ml}$

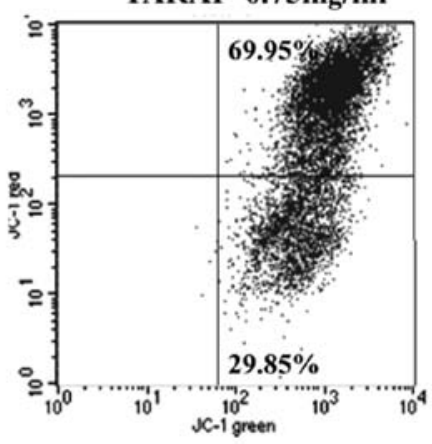

TARAP 0.25mg/ml

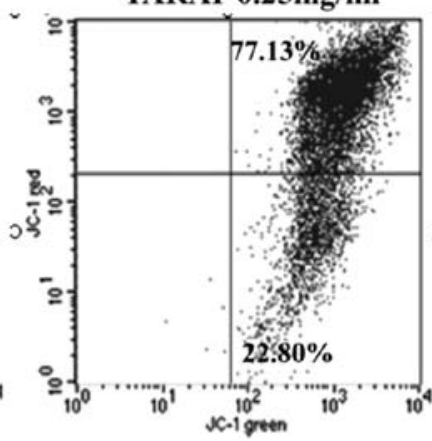

TARAP $1.0 \mathrm{mg} / \mathrm{ml}$

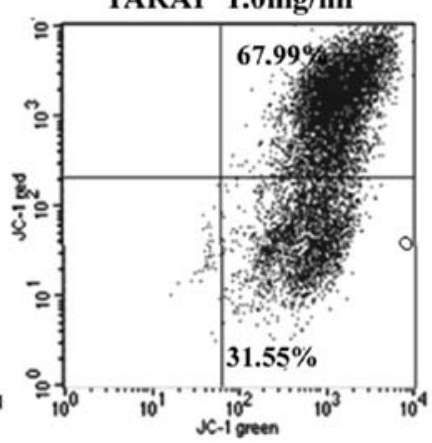

TARAP $0.5 \mathrm{mg} / \mathrm{ml}$

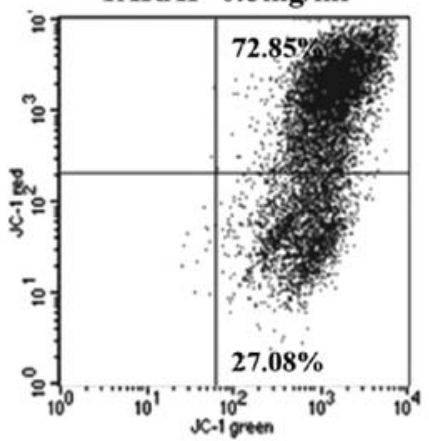

B

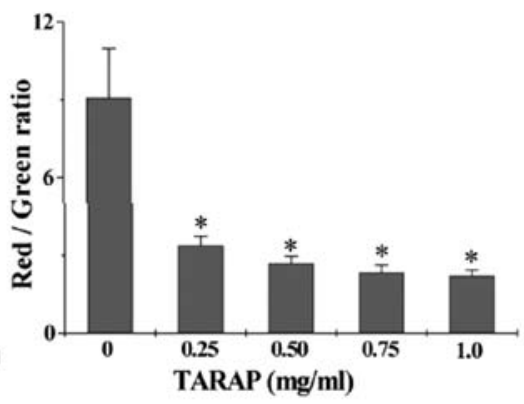

Figure 6. Effect of TARAP on the activity of caspases in HepG2 cells. The cells were treated with the indicated concentrations of TARAP for $24 \mathrm{~h}$. (A) Caspase-3 and (B) caspase-9 activities were determined by a colorimetric assay. The data were normalized to the caspase activities within control cells and presented as 'fold of control'. Data are averages with SD (error bars) from at least three independent experiments. ${ }^{*} \mathrm{P}<0.05$, " $\mathrm{P}<0.01$ vs. control cells.

of both caspase- 9 and caspase- 3 in HepG2 cells $(\mathrm{P}<0.05$ vs untreated control cells).

TARAP upregulates the ratio of pro-apoptotic Bax to anti-apoptotic Bcl-2 in HCC xenograft mice. To further investigate the mechanism of TARAP's pro-apoptotic activity, we performed RT-PCR and IHC analyses to, respectively, determined the mRNA or protein expression of Bcl-2 and Bax in HCC mice. As shown in Fig. 7A, TARAP treatment significantly reduced the mRNA expression of anti-apoptotic
Bcl-2 in HCC tumors, whereas that of pro-apoptotic Bax was significantly increased after TARAP treatment. Consistently, results of IHC assay showed that the protein expression patterns of Bcl-2 and Bax were similar to their respective mRNA levels. The percentage of Bcl-2- or Bax-positive cells in control group was $45.6 \pm 2.67$ or $51.67 \pm 12.37 \%$, whereas that in TARAP-treated mice was $22.5 \pm 5.73$ or $86 \pm 20.36 \%$ (Fig. 7B). Collectively, it is suggested that TARAP promotes hepatocellular carcinoma cell apoptosis via increasing the pro-apoptotic Bax/Bcl-2 ratio. 


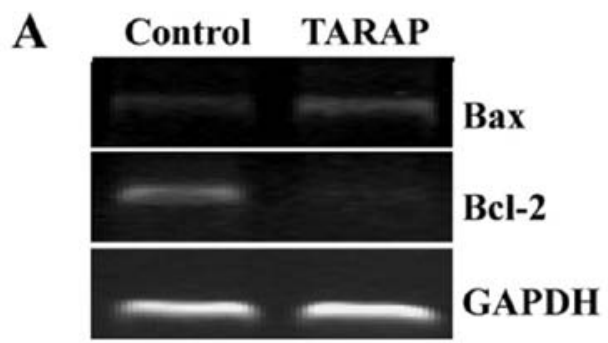

B

B Control
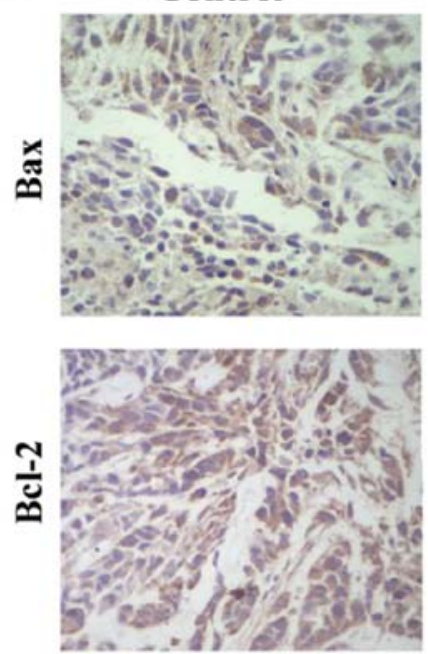

TARAP
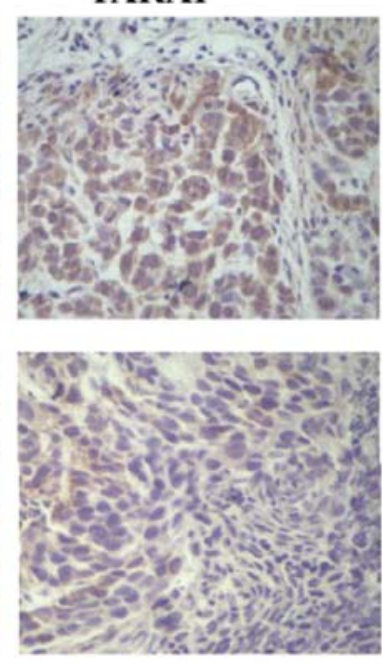
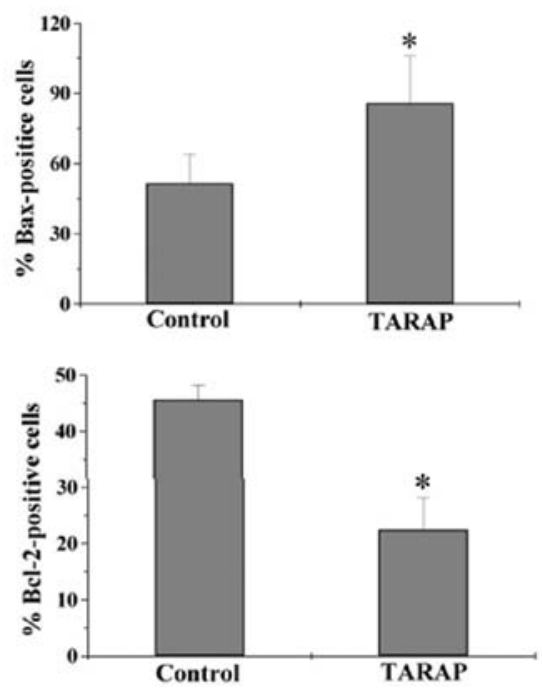

Figure 7. Effect of TARAP on the expression of Bax and Bcl-2 in HCC xenograft mice. (A) The mRNA expression level of Bcl-2 and Bax was determined by RT-PCR. GAPDH was used as the internal control. (B) Tumor tissues were processed for IHC staining for Bcl-2 and Bax. The photographs are representative images taken at a magnification, $\mathrm{x} 400$. Quantification of IHC assay is presented as percentage of positively-stained cells. Data shown were averages with $\mathrm{SD}$ (error bars) from 10 mice in each group. ${ }^{\mathrm{P}}<0.05$ vs. controls.

\section{Discussion}

Cancer cells are characterized by a reduction in cell apoptosis (12), which contributes to drug resistance of tumor cells and thus becomes a major obstacle for the successful management of patients with malignant tumors. Moreover, many currently used anticancer agents contain potent cytotoxicity against normal cells. Drug resistance and adverse effects limits the effectiveness of cancer chemotherapies (30). Therefore, developing novel anticancer agents is urgently needed. Rubus aleaefolius Poir is a natural plant which is typically used to treat various types of hepatitis in Southern part of Fujian Province, China. Recently, Rubus aleaefolius Poir has been reported to possess antitumor activity $(10,11)$. Therefore, before Rubus aleaefolius Poir can be developed as an anticancer agent, its antitumor activity and underlying molecular mechanism should first be elucidated. Using mouse xenograft model and hepatocellular carcinoma cell line, in the present study we found that the total alkaloids of Rubus aleaefolius Poir (TARAP) inhibited cancer growth both in vivo and in vitro, without apparent sign of toxicity. In addition, the inhibitory role of TARAP in cancer growth was due to its pro-apoptotic activity.

The mitochondrion-dependent pathway is the most common apoptotic pathway in vertebrate animal cells. Mitochondrial outer membrane permeabilization (MOMP) is a key commitment step in the induction of cellular apoptosis, since it is the point of convergence for a large variety of intracellular apoptotic signaling pathways leading to the release of many apoptogenic proteins from the mitochondrial intermembrane space. During the process of MOMP, the electrochemical gradient across the mitochondrial membrane collapses. Therefore, the loss of mitochondrial membrane potential is a hallmark for apoptosis. Our data clearly showed that TARAP treatment led to a collapse of mitochondrial membrane potential. Caspases, represented by a family of cysteine proteases, are the key proteins that modulate the apoptotic response. Caspase-3 is a key executioner of apoptosis, which is activated by an initiator caspase such as caspase-9 during mitochondrion-mediated apoptosis. In this study, we found that TARAP induced the activation of caspase- 9 and caspase-3 in hepatocellular carcinoma HepG2 cells in a dosedependent manner. Thus, TARAP induces HepG2 cell death through activation of mitochondrion-dependent pathway.

Members of the Bcl-2 family such as Bax and Bcl-2 proteins have been found to be the most prominent actors in controlling the release of cytochrome $c$ and in the mitochondria-mediated apoptosis pathway (31). The pro-apoptotic Bax translocates to the mitochondria and integrates into the outer mitochondrial membrane, where it induces MOMP resulting in the release of cytochrome $c(16,32)$. In contrast, anti-apoptotic protein Bcl-2 prevents this process by preserving mitochondrial integrity. Therefore, the ratio of Bax to Bcl-2 is critical for determining the fate of cells and higher Bcl-2-to-Bax ratio by aberrant expression of the proteins commonly found in various cancers. 
In this study, we found that TARAP treatment enhanced Bax expression but reduced $\mathrm{Bcl}-2$ expression in tumors of $\mathrm{HCC}$ mice, indicating that TARAP induces mitochondrion-dependent apoptosis through increasing the pro-apoptotic $\mathrm{Bax} / \mathrm{Bcl}-2$ ratio.

In conclusion, here for the first time we demonstrate that the total alkaloids of Rubus aleaefolius Poir inhibits hepatocellular carcinoma growth both in vivo and in vitro via promoting the mitochondrion-dependent apoptosis of cancer cells, which is mediated by the regulation of Bcl-2 family members. Our findings suggest that Rubus aleaefolius Poir may be a potential novel therapeutic agent for cancer treatment.

\section{Acknowledgements}

This study was supported by the Nature Science Foundation of Fujian Province of China (no. 2010J01191 and no. 2010J01194); and the project was sponsored by Medical Originality Foundation of Fujian Province of China (no. 2009-CX-18).

\section{References}

1. Parkin DM, Bray F, Ferlay J and Pisani P: Estimating the world cancer burden: Globocan 2000. Int J Cancer 94: 153-156, 2001.

2. Levin B and Amos C: Therapy of unresectable hepatocellular carcinoma. N Engl J Med 332: 1294-1296, 1995.

3. El-Serag HB, Marrero JA, Rudolph L and Reddy KR: Diagnosis and treatment of hepatocellular carcinoma. J Gastroenterol 134: 1752-1763, 2008.

4. Thomas M: Molecular targeted therapy for hepatocellular carcinoma. J Gastroenterol 44: 136-141, 2009.

5. Newman DJ, Cragg GM and Snader KM: The influence of natural products upon drug discovery. Nat Prod Rep 17: 215-234, 2000.

6. Gordaliza M: Natural products as leads to anticancer drugs. Clin Transl Oncol 9: 767-776, 2007.

7. Tang W and Eisenbrand G: Chinese Drugs of Plant Origin: Chemistry, Pharmacology and Use in Traditional and Modern Medicine. Springer-Verlag, Berlin, 1992.

8. Huang KC: The Pharmacology of Chinese Herbs. 2nd edition. CRC Press, Boca Raton, FL, 1999.

9. Hong ZF: Hepatoprotective effects of Rubus aleaefolius Poir and identification of its active constituents. J Hepatol 129 . 267-272, 2010.

10. Xue H, Aziz RM and Sun N: Inhibition of cellular transformation by berry extracts. Carcinogenesis 22: 351-356, 2001.

11. Lee JH: Activity of crude extract of Rubus crataegifolius roots as a potent apoptosis inducer and DNA to topoisomerase 1 inhibitor. Arch Pharm Res 23: 338-343, 2000.

12. Adams JM and Cory S: The Bcl-2 apoptotic switch in cancer development and therapy. Oncogene 26: 1324-1337, 2007.

13. Borner C: Bcl-2 family members integrators of survival and death. Biochim Biophys Acta 1644: 71-72, 2004.

14. Cory S and Adams JM: The Bcl-2 family: regulators of the cellular life-or-death switch. Nat Rev Cancer 2: 647-656, 2002.
15. Hsu YT, Wolter K and Youle RJ: Cytosol to membrane redistribution of members of the Bcl-2 family during apoptosis. Proc Natl Acad Sci USA 94: 3668-3672, 1997.

16. Wolter KG: Movement of Bax from the cytosol to mitochondria. J Cell Biol 139: 1281-1292, 1997.

17. Yang J, Liu X, Bhalla K, Kim CN, Ibrado AM, Cai J, Peng TI, Jones DP and Wang X: Prevention of apoptosis by Bcl-2: release of cytochrome $\mathrm{c}$ from mitochondria blocked. Science 275: 1129-1132, 1997.

18. Antonsson B, Montessuit S, Lauper S, Eskes R and Martinou JC: Bax oligomerization is required for channel-forming activity in liposomes and to trigger cytochrome $\mathrm{c}$ release from mitochondria. Biochem J 345: 271-278, 2000.

19. Jürgensmeier JM, Xie Z, Deveraux Q, Ellerby L, Bredesen D and Reed JC: Bax directly induces release of cytochrome $\mathrm{c}$ from isolated mitochondria. Proc Natl Acad Sci USA 95: 4997-5002, 1998.

20. Kluck RM, Bossy-Wetzel E, Green DR and Newmeyer DD: The release of cytochrome c from mitochondria: a primary site for Bcl-2 regulation of apoptosis. Science 275: 1132-1136, 1997.

21. Gross A, McDonnell JM and Korsmeyer SJ: Bcl-2 family members and the mitochondria in apoptosis. Genes Dev 13: 1899-1911, 1999.

22. Thomenius MJ, Wang NS, Reineks EZ, Wang Z and Distelhorst $\mathrm{CW}$ : $\mathrm{Bcl}-2$ on the endoplasmic reticulum regulates Bax activity by binding to BH3-only proteins. J Biol Chem 278: 6243-6250, 2003.

23. Antonsson B, Conti $\mathrm{F}$ and Ciavatta A: Inhibition of Bax channel-forming activity by Bcl-2. Science 277: 370-372, 1997.

24. Youle RJ and Strasser A: The BCL-2 protein family: opposing activities that mediate cell death. Nat Rev Mol Cell Biol 9: 47-59, 2008.

25. Yip KW and Reed JC: Bcl-2 family proteins and cancer. Oncogene 27: 6398-6406, 2008.

26. Lin JM, Zhao JY, Li TJ, Zhou JH, Hu J and Hong ZF: Hepatoprotection in a rat model of acute liver damage through inhibition of CY2E1 activity by total alkaloids extracted from Rubus alceifolius Poir. Int J Toxicol 30: 237-243, 2010.

27. Singh RP, Dhanalakshmi S, Tyagi AK, Chan DCF, Agarwal C and Agarwal R: Dietary feeding of silibinin inhibits advance human prostate carcinoma growth in athymic nude mice, and increases plasma insulin-like growth factor-binding protein-3 levels. Cancer Res 62: 3063-3069, 2002.

28. Resendes AR, Majó N, Segalés J, Espadamala J, Mateu E, Chianini F, Nofrarías M and Domingo M: Apoptosis in normal lymphoid organs from healthy normal, conventional pigs at different ages detected by TUNEL and cleaved caspase-3 immunohistochemistry in paraffin-embedded tissues. Vet Immunol Immunopathol 99: 203-213, 2004.

29. Yang JX, Wang YL, Bao Y and Guo J: The total flavones from Semen cuscutae reverse the reduction of testosterone level and the expression of androgen receptor gene in kidney-yang deficient mice. J Ethnopharmacol 119: 166-171, 2008.

30. Boose $\mathrm{G}$ and Stopper H: Genotoxicity of several clinically used topoisomerase II inhibitors. Toxicol Lett 116: 7-16, 2000.

31. Borner C: The Bcl-2 protein family: sensors and checkpoints for life-or-death decisions. Mol Immunol 39: 615-647, 2003.

32. Ow YP, Green DR, Hao Z and Mak TW: Cytochrome c: functions beyond respiration. Nat Rev Mol Cell Biol 9: 532-542, 2008. 